\title{
One year follow-up study of endocrine and lung function of asthmatic children on inhaled budesonide
}

\author{
W.H. Nikolaizik*, M.A. Preece**, J.O. Warner+
}

\begin{abstract}
One year follow-up study of endocrine and lung function of asthmatic children on inhaled budesonide. W.H. Nikolaizik, M.A. Preece, J.O. Warner. CERS Journals Ltd 1997.

ABSTRACT: Inhaled corticosteroids have become a mainstay in the management of chronic asthma. Their use had been considered safe, although some degree of adrenal suppression has been demonstrated after 2 and 4 weeks of treatment with either $400 \mu \mathrm{g} \cdot$ day $^{-1}$ of beclomethasone dipropionate or budesonide.

To weigh the benefits and risks of long-term treatment, 12 children with moderately severe asthma were assessed in a follow-up study on budesonide $200 \mu \mathrm{g}$ b.i.d.

After $1 \mathrm{yr}$, the nocturnal cortisol production was significantly reduced by $19 \%$, but no greater compared to 2 and 4 weeks of treatment. Growth and growth hormone levels were normal. Lung function tests were significantly better, not only versus baseline values but also versus 2 and 4 weeks of treatment.

We conclude that systemic effects of inhaled corticosteroids in conventionally low doses do not accumulate with length of treatment, whilst lung function parameters will continue to improve. Therefore, inhaled corticosteroids once started in asthmatic children not controlled on other medications should be continued, but their use should be carefully considered and the minimal dose required to control the asthma employed.
\end{abstract}

Eur Respir J 1997; 10: 2596-2601.

Inhaled corticosteroids (ICS) are the principal drugs used in the management of moderate-to-severe childhood as well as adult asthma [1, 2]. However, awareness of the possible systemic effects of ICS in children has been a source of concern, particularly when they are used in high doses [3]. Previous studies of the systemic effects of ICS have employed very insensitive techniques, such as the measurement of morning cortisol, and have failed to show any significant effect even at moderately high doses [4]. However, integrated overnight plasma cortisol concentrations or urinary-free cortisol have been suggested as more sensitive tests of reduced hypothalamic pituitary adrenal axis function and as being superior to stimulation tests $[5,6]$.

In a cross-sectional study of plasma cortisol measured every 20 min during sleep in 19 asthmatic children, we demonstrated that there was a dose-related effect of inhaled beclomethasone dipropionate (BDP) on overnight cortisol production, despite the fact that there was no difference in the height of the morning peak of cortisol [7]. As this study did not account for the effect of asthma itself, we conducted a subsequent prospective cross-over study of integrated plasma cortisol concentrations and urinary-free cortisol in 12 children commencing ICS for the first time. Both BDP or budesonide (BUD), at a dose of $200 \mu \mathrm{g}$ b.i.d. for 2 weeks in randomized order, caused identical significant suppressive effects on overnight cortisol production [8]. We found similar suppression in a controlled study administering either a single dose of $400 \mu \mathrm{g}$ of BUD in the evening
*Alpine Children's Hospital, Davos, Switzerland. **Institute of Child Health, University of London, London, UK. ${ }^{+}$Child Health, University of Southampton, Southampton, UK.

Correspondence: J.O. Warner Child Health

Mailpoint 803

Southampton General Hospital

Southampton SO16 6YD

UK

Keywords: Cortisol

growth

inhaled corticosteroids

lung function

Received: February 121997

Accepted after revision July 51997 to healthy adults, or administering $400 \mu \mathrm{g}$ twice daily for 2 weeks [9].

The above studies were of very short duration and there remained a concern that there might be a cumulative effect of continuing ICS over longer periods. Indeed, nocturnal serum cortisol production was reduced by $27 \%$ after 2 weeks and 35\% after 4 weeks of treatment in the paediatric study, with similar apparent increases in effects in suppression of urinary-free cortisol (33 and 48\%, respectively). We therefore, repeated the studies on the same patients after 1 year of treatment, to establish whether there was a cumulative effect. We report the results of this 1 year follow-up study.

\section{Patients and methods}

Twelve asthmatic children, inadequately controlled on sodium cromoglycate combined with beta-agonists and/or optimal doses of slow-release theophyllines, had completed our previous 4 week study. None of these patients had previously used any regular topical or systemic corticosteroids. At the end of this period, all 12 children and their parents agreed to proceed with the study for another year. The treatment was continued with BUD $200 \mu \mathrm{g}$ administered from a metered-dose inhaler (MDI) b.i.d. The follow-up was only of those patients who: showed no dramatic changes in inhaled steroid requirement and had no oral steroid therapy; and obviously those who had a complete follow-up. Thus, there 
were two exclusions: a child who had a dramatic increase in inhaled steroid requirements and the need for courses of oral steroids; and a child who died 8 months after the start of the study. The latter case is reported in a separate paper. These children were replaced by two other patients, who had full evaluations after the previous study had already been completed.

Monitoring at home included: daily diary card recordings of asthma symptoms (on a standard 0-3 scale); twice daily measurement of peak expiratory flow (PEF) rates; number of $\beta_{2}$-agonist puffs; and adverse experiences. PEF rates were recorded as the best of three blows each morning and evening before treatment. All children inhaled a recommended dose of $\beta_{2}$-agonist regularly, e.g. terbutaline or salbutamol, two puffs from a MDI b.i.d. prior to the prophylactic BUD (Pulmicort ${ }^{\circledR}$ Astra Pharmaceuticals Ltd, Kings Langley, UK). In addition, extra doses of $\beta_{2}$-agonists could be used as required. Short courses of systemic steroids for up to 7 days might be given for acute attacks. Children using systemic or inhaled corticosteroid medications other than the trial drugs regularly for more than 7 days were excluded from the study. The patients were seen in the out-patients department at 2 monthly intervals for evaluation. The bronchial challenge tests were performed in the paediatric respiratory laboratory using a modification of the method of COCKCROFT and co-workers [10, 11]. The provocative concentration of histamine causing a $20 \%$ fall in forced expiratory volume in one second (PC20) was calculated.

After $1 \mathrm{yr}$ of treatment, the children were admitted to hospital for $36 \mathrm{~h}$ for detailed assessment. They attended the clinic in the afternoon and were settled on the ward attached to monitors for an acclimatization night. The following afternoon, an intravenous cannula was inserted into a forearm or cubital vein to ensure venous access during the night without disturbing the patient's sleep. For inserting the cannula, Emla ${ }^{\circledR}$ (Astra Pharmaceuticals Ltd) cream was used, a topical anaesthetic agent that has been shown to be effective in eliminating the pain of percutaneous punctures [12].

At night, small blood samples were taken every 20 min from 22:00 to 10:00 $\mathrm{h}$ for evaluation of cortisol and growth hormone $(\mathrm{GH})$ levels, and at midnight and 08:00 $\mathrm{h}$ the next morning for measurement of adrenocorticotrophic hormone (ACTH). An extra sample was taken for full blood count and measurement of immunoglobulins, including total immunoglobulin $\mathrm{E}(\mathrm{IgE})$. Urinary-free cortisol was measured in $24 \mathrm{~h}$ urine collections split into three portions: the first portion from 10:00 $\mathrm{h}$ to bedtime; the second from bedtime to awakening; and the third from awakening to 10:00 h. Cortisol was measured by means of a radioimmunoassay with a I ${ }^{125}$-labelled cortisol derivate and cellulose-bound antibodies (Bioanalysis Ltd, Cardiff, UK). The coefficient of variation $(\mathrm{CV})$ within assay is $5.4 \%$. Both serum and urine were analysed with this method.

Human GH was measured by means of an immunoradiometric assay (IRMA) using a sheep anti-GH antiserum and a mouse monoclonal anti-GH antibody (North East Thames Region Immunoassay Unit (NETRIA)). The labelled antibody was prepared by radioiodination of a purified monoclonal antibody. The sensitivity of this specific assay is $0.2 \mathrm{mU} \cdot \mathrm{L}^{-1}$.
ACTH was measured by double-antibody radioimmunoassay from Diagnostic Products Corp. (Glyn Rhanwy, Caernaryon, UK). The sensitivity is $7 \mathrm{pg} \cdot \mathrm{mL}^{-1}$ (Medical Research Council (MRC) 74/555), with an intra-assay $\mathrm{CV}$ of $14 \%$ at $22 \mathrm{pg} \cdot \mathrm{mL}^{-1}$ and $4.0 \%$ at $190 \mathrm{pg} \cdot \mathrm{mL}^{-1}$; the interassay $\mathrm{CV}$ is $14 \%$ at $22 \mathrm{pg} \cdot \mathrm{mL}^{-1}$ and $6.6 \%$ at 212 $\mathrm{pg} \cdot \mathrm{mL}^{-1}$.

Height was measured with a stadiometer: five measurements were taken in the morning at 09:00 h, and the calculated mean was accepted if the difference between highest and lowest values did not exceed $0.2 \mathrm{~cm}$. The standard deviation (SD) scores for velocity of growth in height were calculated according to age from measurements taken at the beginning and end of the study, using the following formula: height velocity SD score $=$ (height velocity - mean height velocity for age)/SD of height velocity for age. Bone ages were determined by the TW2 method [13].

At night, oxygen saturation and pulse were recorded with a pulse oximeter N100 (Nellcor®: Nellcor, Bicester, Oxon, UK) pulsed oximeter N100, and breath rates were counted in $20 \mathrm{~min}$ intervals. By day, flow-volume curves (forced vital capacity (FVC), forced expiratory volume in one second (FEV1), forced expiratory flow at 50 and $25 \%$ FVC (FEF50, FEF25)) were recorded every $2 \mathrm{~h}$ from 10:00 $\mathrm{h}$ to bedtime, and again from awakening to 10:00 $\mathrm{h}$ the next morning using a Vitalograph $\AA$ (Vitalograph ${ }^{\circledR}$, Buckingham, UK). In addition, whole body plethysmography (functional residual capacity (FRC) and airway resistance (Raw)) was performed in the respiratory laboratory. To be able to compare the results with those of $1 \mathrm{yr}$ previously, the results were described as percentage of predicted values by height [14].

The declaration of Helsinki was always followed. The patients and their parents were informed verbally and in writing about the trial and volunteered to participate. Informed consent was obtained from all parents. The children and their parents were free to withdraw from the study at any time. Approval from the local Research Ethics Committee was obtained before the start of the study. The children's parents were informed that the results were stored and analysed in a computer but that the identification of their child was not possible by any person other than the investigator.

\section{Statistics}

Data were analysed with the Systat@ system for statistics 5.02 (Systat Inc., Illinois, USA). The various parameters obtained during the trial were compared with the entry values using the paired Wilcoxon test. For estimating the nocturnal serum-cortisol production, the area under the curve (AUC) was calculated using Simpson's rule for data points spaced equidistantly. For comparison of monthly peak flow variabilities, the $\mathrm{CV}$ was calculated: it is defined as SD divided by the mean given as a percentage.

\section{Results}

Twelve children, nine boys and three girls, completed the follow-up study. All 12 children used BUD 200 $\mu \mathrm{g}$ b.i.d. twice daily throughout the study period. None 
of them had a severe asthma attack requiring systemic corticosteroids or hospital attendance, except for the regular visits. Side-effects due to the study medication did not occur, with neither hoarseness of voice nor candidiasis of mouth or throat.

The age $($ mean $\pm \mathrm{SD})$ of the study patients was $10.8 \pm$ $2.1 \mathrm{yrs}$ at the beginning of the trial and $11.8 \pm 2.0 \mathrm{yrs}$ at the end. Corresponding bone ages did not differ significantly from chronological age ( $\mathrm{p}>0.05$, Wilcoxon-test): $10.8 \pm 1.9$ yrs and $12.0 \pm 2.0$, respectively. The mean height was $143.0 \pm 13.4 \mathrm{~cm}$ at the beginning of the trial and $148.0 \pm 14.7 \mathrm{~cm}$ at the end of the study. The velocity of growth in height was higher than expected in four children and lower in eight children. The mean velocity of growth in height was $5.4 \pm 2.1 \mathrm{~cm} \cdot \mathrm{yr}^{-1}$, and the mean SD score for velocity was $-0.5 \pm 1.5 \mathrm{~cm} \cdot \mathrm{yr}^{-1}$. Neither velocities of growth in height nor SD scores for velocity of growth in height were significantly different from expected values ( $p>0.05$, Wilcoxon-test). No child showed evidence of pubertal development at the end of the study.

The results of the diary card recordings at home are summarized in table 1. All children had asthma symptoms at the beginning of the study, so that the treatment with ICS had to be commenced as soon as possible; therefore, prestudy recordings could not be made. During the study period, the asthma symptom score and additional $\beta$-agonist usage were continuously low. Four patients on long-acting theophyllines were able to stop this drug during the course of the trial. The PEF rates increased progressively over 10 months, and the PEF variability decreased slightly, reaching a minimum after 10 months of treatment.

Bronchial histamine challenges showed a significant improvement in PC20 after 2 months of treatment ( $\mathrm{p}=$ 0.013 Wilcoxon-test) (table 1). In the following months, PC20 was consistently higher compared with the baseline values, but was only significantly different at 8 months $(\mathrm{p}=0.037)$ and 10 months $(\mathrm{p}=0.032)$.
The nocturnal GH production increased by $22 \%$ after 1 year of treatment compared with the baseline values, but the difference was not significant (table 2). However, there was a significant increase of 38 and $27 \%$ compared with investigations after 2 and 4 weeks of treatment with ICS ( $\mathrm{p}=0.02$ and $\mathrm{p}=0.04$, respectively, Wilcoxon test). The number of $\mathrm{GH}$ peaks at night (that reached levels above $10 \mathrm{mU} \cdot \mathrm{L}^{-1}$ ), was $2.8 \pm 1.3$ at baseline, $2.5 \pm$ 1.5 after the first 2 weeks, $2.2 \pm 1.3$ after the first 4 weeks, and $2.9 \pm 0.7$ after 1 year of treatment with inhaled BUD. None of the differences were significant.

The mean serum cortisol levels are displayed in figure 1. There was a considerable delay in the early morning rise in cortisol secretion but the cortisol levels reached

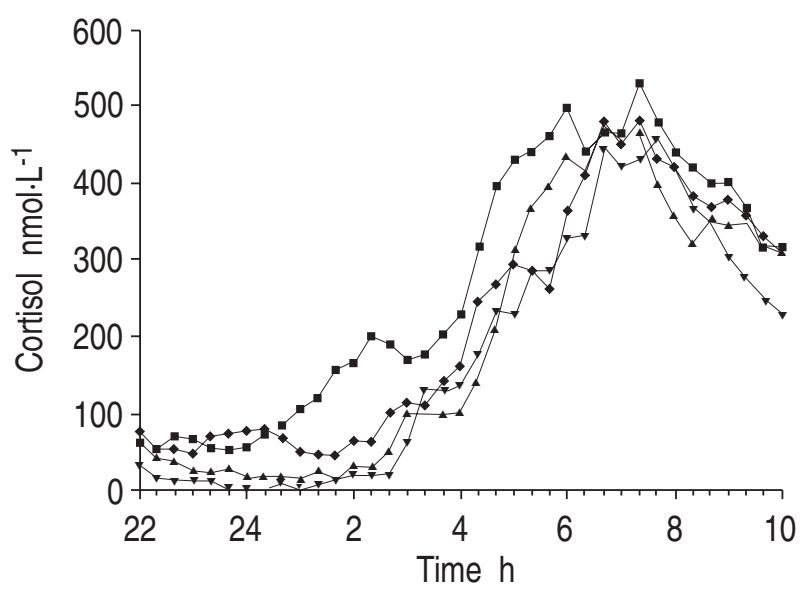

Fig. 1. - Nocturnal cortisol secretion profiles measured every 20 min overnight from 22:00 $\mathrm{h}$ until 10:00 $\mathrm{h}$ the following day, as a mean of the levels at each time-point for the 12 children in the study. baseline, before commencing inhaled steroids; _ : after 2 weeks; $\checkmark$ : after 4 weeks; $\longrightarrow$ : after 1 yr. There is significant suppression of cortisol production during the night between 01:00 $\mathrm{h}$ and 06:00 $\mathrm{h}$ with a delayed rise to the morning peak, which is nonsignificantly different at any of the time-points after commencing inhaled corticosteroid.

Table 1. - Diary card recordings and histamine challenge results

\begin{tabular}{|c|c|c|c|c|c|c|c|}
\hline & Baseline & Month 1-2 & Month 3-4 & Month 5-6 & Month 7-8 & Month 9-10 & Month 11-12 \\
\hline Daily symptom score $(0-4)$ & - & $0.29 \pm 0.32$ & $0.21 \pm 0.39$ & $0.22 \pm 0.36$ & $0.18 \pm 0.20$ & $0.16 \pm 0.27$ & $0.26 \pm 0.36$ \\
\hline Daily use of $\beta_{2}$-agonist $\mathrm{mg}$ & - & $1.00 \pm 1.33$ & $0.93 \pm 1.34$ & $0.95 \pm 1.33$ & $0.99 \pm 1.32$ & $0.99 \pm 0.89$ & $0.86 \pm 0.53$ \\
\hline Mean morning PEF L $\cdot \mathrm{min}^{-1}$ & - & $285 \pm 24$ & $310 \pm 23$ & $318 \pm 26$ & $322 \pm 23$ & $325 \pm 18$ & $323 \pm 21$ \\
\hline Mean evening PEF $\mathrm{L} \cdot \mathrm{min}^{-1}$ & - & $290 \pm 24$ & $310 \pm 21$ & $324 \pm 23$ & $324 \pm 25$ & $328 \pm 20$ & $324 \pm 21$ \\
\hline Morning PEF variability $\%$ & - & $9.4 \pm 5.3$ & $8.3 \pm 4.9$ & $9.5 \pm 7.0$ & $7.5 \pm 4.2$ & $7.3 \pm 4.8$ & $8.1 \pm 10.3$ \\
\hline Evening PEF variability $\%$ & - & $9.3 \pm 5.6$ & $7.7 \pm 5.2$ & $7.8 \pm 4.1$ & $8.4 \pm 5.8$ & $7.4 \pm 5.3$ & $7.7 \pm 8.4$ \\
\hline Histamine $\mathrm{PC}_{20} \mathrm{mg} \cdot \mathrm{mL}^{-1}$ & $2.9 \pm 4.8$ & $6.6 \pm 7.8 *$ & $6.3 \pm 11.1^{+}$ & $4.2 \pm 4.9$ & $9.1 \pm 13.6^{*}$ & $6.3 \pm 6.7 *$ & $5.5 \pm 8.9^{+}$ \\
\hline
\end{tabular}

Data are presented as mean \pm SD. PEF: peak expiratory flow; PC20: provocative concentration of histamine causing a $20 \%$ fall in forced expiratory volume in one second. ${ }^{+}: \mathrm{p}<0.10 ;{ }^{*}: \mathrm{p}<0.05$ versus baseline value.

Table 2. - Endocrine function tests

\begin{tabular}{|c|c|c|c|c|}
\hline & Baseline & After 2 weeks & After 4 weeks & After 1 year \\
\hline $12 \mathrm{~h}$ serum $\mathrm{GH}(20: 00-10: 00 \mathrm{~h}) \mathrm{mU} \cdot \mathrm{L}^{-1}$ & $99.0 \pm 43.2$ & $87.4 \pm 51.4$ & $94.9 \pm 58.4$ & $121.2 \pm 71.4^{\# \S}$ \\
\hline $12 \mathrm{~h}$ serum cortisol $(20: 00-10: 00 \mathrm{~h}) \mathrm{nmol} \cdot \mathrm{L}^{-1}$ & $3175 \pm 458$ & $2367 \pm 582 * *$ & $2118 \pm 566 * *$ & $2566 \pm 825 *$ \\
\hline Serum ACTH $(24: 00 \mathrm{~h}) \mathrm{mU} \cdot \mathrm{L}^{-1}$ & $29.4 \pm 12.0$ & $25.2 \pm 8.8$ & $23.4 \pm 11.7$ & $27.2 \pm 6.9$ \\
\hline Serum ACTH $(08: 00 \mathrm{~h}) \mathrm{mU} \cdot \mathrm{L}^{-1}$ & $28.3 \pm 9.8$ & $25.0 \pm 7.6$ & $20.8 \pm 10.0$ & $31.9 \pm 7.7^{+\# \S}$ \\
\hline Urine cortisol (10:00 h-bedtime) nmol & $1237 \pm 616$ & $967 \pm 699$ & $657 \pm 538$ & $1134 \pm 1106$ \\
\hline Urine cortisol (bedtime-awakening) nmol & $1204 \pm 613$ & $847 \pm 474^{*}$ & $543 \pm 387 * *$ & $618 \pm 501 *$ \\
\hline Urine cortisol (awakening-10:00 h) nmol & $1009 \pm 978$ & $933 \pm 579$ & $933 \pm 543$ & $610 \pm 279$ \\
\hline Urine cortisol (bedtime-10:00 h) nmol & $2212 \pm 1348$ & $1780 \pm 858$ & $1474 \pm 844^{*}$ & $1229 \pm 699 *$ \\
\hline $24 \mathrm{~h}$ urine cortisol nmol & $3449 \pm 1621$ & $2747 \pm 1332 *$ & $2134 \pm 1022 * *$ & $2363 \pm 1608 *$ \\
\hline
\end{tabular}

Data are presented as mean \pm SD. GH: growth hormone; ACTH: adrenocorticotrophic hormone. + : $\mathrm{p}<0.10 ; *$ : $\mathrm{p}<0.05 ; * *$ : $\mathrm{p}<0.005$ versus baseline; \#: $\mathrm{p}<0.05$ versus "After 2 weeks"; §: $\mathrm{p}<0.05$ versus "After 4 weeks". 
Table 3. - Lung function tests

\begin{tabular}{|c|c|c|c|c|}
\hline & Baseline & $\begin{array}{c}\text { After } \\
2 \text { weeks }\end{array}$ & $\begin{array}{c}\text { After } \\
4 \text { weeks }\end{array}$ & $\begin{array}{l}\text { After } \\
1 \text { year }\end{array}$ \\
\hline FVC \% & $81 \pm 19$ & $88 \pm 13 *$ & $87 \pm 13 *$ & $90 \pm 9.3 * *$ \\
\hline FEV1 \% & $68 \pm 20$ & $76 \pm 14 * *$ & $76 \pm 15^{* * *}$ & $83 \pm 10 * * * \# \S$ \\
\hline FEF50 $\%$ & $58 \pm 29$ & $70 \pm 24 * * *$ & $69 \pm 27 * * *$ & $78 \pm 22 * * * \S$ \\
\hline FEF25 \% & $58 \pm 34$ & $63 \pm 26$ & $67 \pm 35 * *$ & $77 \pm 28 * * * \# \#$ \\
\hline FRC \% & $123 \pm 24$ & $117 \pm 21$ & $114 \pm 21$ & $102 \pm 15$ *\# \\
\hline Raw \% & $186 \pm 151$ & $111 \pm 38$ & $149 \pm 81$ & $117 \pm 56$ \\
\hline
\end{tabular}

Data are presented as mean \pm SD. FVC: forced vital capacity; FEV1: forced expiratory volume in one second; FEF50 and FEF25: forced expiratory flow at 50 and $25 \%$ FVC, respectively; FRC: functional residual capacity; Raw: airway resistance. *: $\mathrm{p}<0.05 ; * *: \mathrm{p}<0.005 ; * * *: \mathrm{p}<0.0001$ versus baseline; \#: $\mathrm{p}<0.05$; \#\#: $\mathrm{p}<0.005$ versus "After 2 weeks"; $\$$ : $\mathrm{p}<0.05$; $\$$ : $\mathrm{p}<0.005$ versus "After 4 weeks".

normal maximum values. The total nocturnal cortisol production, calculated as AUC, was significantly reduced by $19 \%$ compared with the baseline values $(\mathrm{p}=0.045$, Wilcoxon test). However, there was no significant difference as compared to the cortisol production after the first 2 or 4 weeks of treatment (table 2).

There was also a lower urinary cortisol production in all three portions, and a significant difference of $49 \%$ in the second portion from bedtime to awakening ( $\mathrm{p}=$ 0.04, Wilcoxon test). The combined second and third portion from bedtime to $10: 00 \mathrm{~h}$ revealed a $44 \%$ decrease $(p=0.04)$ and the $24 \mathrm{~h}$ urine a $32 \%$ decrease $(\mathrm{p}=0.02)$ compared with the baseline values. Again, no significant difference was found as against the urinary cortisol after the first 2 or 4 weeks of treatment (table 2).

The ACTH levels at midnight were slightly lower compared with the baseline values, and slightly higher as compared to the first 2 and 4 weeks of treatment; the differences were nonsignificant. The ACTH levels at 08:00 h after $1 \mathrm{yr}$ of treatment were increased by $13 \%$ compared with the baseline values $(\mathrm{p}=0.06$, Wilcoxon test), and there was a significant increase of $27 \%$ compared with 2 weeks $(\mathrm{p}=0.05)$ and $53 \%$ compared with 4 weeks of treatment $(\mathrm{p}=0.01)$ (table 2$)$. The full differential blood count and the levels of immunoglobulins $\mathrm{A}, \mathrm{M}, \mathrm{G}$ and $\mathrm{E}$ were nonsignificantly different compared with the baseline values. The mean IgE level was 696 (range 55-2,280) IU.mL $\mathrm{mL}^{-1}$ at the beginning and 720 (range $65-2,740$ ) IU. $\mathrm{mL}^{-1}$ at the end of the study.

Daily profiles of FVC, FEF50 and FEF25 essentially paralleled the curves of FEV1. The mean lung function data are summarized in table 3: after $1 \mathrm{yr}$ of treatment with BUD, the FVC improved significantly by $11 \%$ compared to baseline values $(\mathrm{p}=0.0004)$; and FEV1 improved by $21 \%$ versus baseline $(\mathrm{p}<0.0001)$, by $8 \%$ versus 2 weeks $(\mathrm{p}=0.01)$ and by $9 \%$ versus 4 weeks of treatment $(\mathrm{p}=0.001)$. FEF50 was 34\% higher compared with baseline $(\mathrm{p}<0.0001)$ and $14 \%$ higher compared with 4 weeks of treatment $(p=0.02)$. FEF25 was $33 \%$ higher compared with baseline $(\mathrm{p}<0.0001), 22 \%$ higher compared with 2 weeks $(\mathrm{p}=0.001)$ and $15 \%$ higher compared with 4 weeks of treatment $(\mathrm{p}=0.035)$. After 1 $\mathrm{yr}$ of treatment with BUD, the FRC revealed $17 \%$ less overinflation compared with baseline $(\mathrm{p}=0.02)$, and $13 \%$ compared with the first 2 weeks of treatment $(\mathrm{p}=0.045)$. The Raw was $37 \%$ lower compared with baseline; however, this difference was nonsignificant.
The overnight oxygen saturations and breathing rates were always in the normal range. The oxygen saturation was $97.3 \pm 1.9 \%$ at baseline, $97.8 \pm 0.8 \%$ after 2 weeks, $98.2 \pm 0.8 \%$ after 4 weeks, and $97.6 \pm 0.5 \%$ after $1 \mathrm{yr}$. The breathing rate was $17.0 \pm 1.6$ breaths $\cdot \mathrm{min}^{-1}$ at baseline, $16.4 \pm 1.6$ breaths $\cdot \mathrm{min}^{-1}$ after 2 weeks, $16.4 \pm 1.3$ breaths $\cdot \mathrm{min}^{-1}$ after 4 weeks, and $17.0 \pm 1.2$ breaths $\cdot \mathrm{min}^{-1}$ after $1 \mathrm{yr}$.

\section{Discussion}

Inhaled corticosteroids have become the principal treatment for chronic persistent asthma in childhood $[1,2]$. They were considered to be devoid of systemic effects, at least in conventional low doses, until we demonstrated nocturnal cortisol suppression even at a relatively low dose of $400 \mu \mathrm{g} \cdot \mathrm{day}^{-1}$ BDP or BUD [7, 8]. These studies did not take into account the effect of the asthma itself, but a placebo-controlled study in healthy adult volunteers finally confirmed that the suppressive effect was due to the drug and not related to the underlying problem, namely asthma [9]. To assess the clinical relevance of these findings, we performed a follow-up study in asthmatic children. There was no further accumulation of adrenal suppression after $1 \mathrm{yr}$ of treatment with BUD, with similar nocturnal cortisol suppression compared with 2 and 4 weeks of treatment. From the split urine portions, the maximal suppression occurred at night, whilst the cortisol production by day was nonsignificantly reduced. Therefore, the $24 \mathrm{~h}$ cortisol reduction in the present study was due mainly to nocturnal suppression.

Our results are supported by another study measuring the $24 \mathrm{~h}$ integrated concentration of plasma cortisol in 10 children, aged 10-14 yrs, with chronic asthma [15]. Treatment with BDP $200 \mu \mathrm{g}$ b.i.d. for 3 months caused adrenal suppression in all children. The maximal reduction in cortisol secretion occurred between 20:00 and 02:00 $\mathrm{h}$ after the evening inhalation at 19:00 $\mathrm{h}(63 \%)$, compared with a $29 \%$ reduction between 08:00 and 14:00 $\mathrm{h}$ after the morning dose. The same group reported the effect of long-term therapy with inhaled BDP on the pituitary-adrenal axis [16]. Eight children, aged 6-16 yrs, with asthma inhaled BDP in doses ranging 200 to $450 \mu \mathrm{g} \cdot \mathrm{day}^{-1}$ for 6 months to $4 \mathrm{yrs}$. The mean integrated concentration of plasma cortisol was $46 \%$ lower in the treatment group than in a control group, consisting of six children of the same age, who had the assessment as part of an endocrinological evaluation and were found to be healthy. It was concluded that long-term therapy, even with relatively conventional doses of inhaled BDP, may cause reduction in the normal physiological secretion of cortisol. The present study shows the same result on long-term BUD. However, these data reveal for the first time that there was no cumulative effect after continuing treatment for $1 \mathrm{yr}$.

A recent study investigated the effect of inhaled BDP, administered at a dose of $400 \mu \mathrm{g} \cdot \mathrm{day}^{-1}$ for 7 months, on the linear growth in 94 children with mild asthma aged 7-9 yrs [17]. At the end of the 7 months, the BDP-treated children had grown significantly less than the children on placebo, and there was no significant catch-up growth during a wash-out period of 4 months. It was 
concluded that BDP, at a dose taken by many children, significantly decreased statural growth in those with mild asthma. In the present $1 \mathrm{yr}$ follow-up study, growth was nonsignificantly reduced on the same dose of BUD, 400 $\mu \mathrm{g} \cdot \mathrm{day}^{-1}$. However, our patients had considerably more severe disease than those described by Doull et al. [17], who would not be considered to need ICS based on published guidelines $[1,2]$. In the present study, the mean SD score for velocity of growth in height was -0.52 , which is in accordance with a study of 58 prepubertal children attending a specialist asthma clinic with poorlycontrolled chronic asthma [18]. There was no evidence that the administration of BDP or BUD at a dose of 200-1,600 $\mu \mathrm{g} \cdot \mathrm{day}^{-1}$, mean $800 \mu \mathrm{g} \cdot \mathrm{day}^{-1}$, had an adverse effect on growth. The SD score for velocity of growth in height was maximal when the asthma was well controlled both before and after starting ICS, and was least when the asthma was poorly controlled. The authors were able to show a significant correlation between the effectiveness of control and the height velocity SD score for velocity of growth in height, both before and after ICS were started [18]. In the present $1 \mathrm{yr}$ follow-up study, the nocturnal GH secretion was normal on BUD $400 \mu \mathrm{g} \cdot \mathrm{day}^{-1}$. The absolute $\mathrm{GH}$ production was higher compared with the baseline values, and the difference was significant compared with the first 2 or 4 weeks of treatment. This increase may reflect the beginning of a growth spurt, due to the imminent onset of puberty in some patients.

Inhaled corticosteroids have greatly improved the management of childhood asthma [3, 19]. The present study was not designed to investigate efficacy, which would have required placebo control. However, other medications could be reduced, the morning and evening PEF rates increased and their variabilities decreased. Overall, the diary cards showed better asthma control with continuing treatment, reaching a maximum after 10 months. After $1 \mathrm{yr}$, the lung function tests revealed significant improvement, not only versus baseline values but also versus the first 2 or 4 weeks of treatment. These improvements included an increase in expiratory flow parameters as well as a decrease of overinflation. Histamine challenge thresholds were higher than baseline values throughout the whole study period, and a significant increase in $\mathrm{PC} 20$ was shown for the first time after 2 months. In the following months, the results varied with a significant improvement reached again after 8 and 10 months.

While these results might reflect spontaneous change over time, they are in accordance with a well-known study by KERREBIJN et al. [20], who investigated the effect of long-term treatment with ICS or $\beta$-agonists on the bronchial responsiveness in children with asthma. Twelve children aged 7-16 yrs, were treated with BUD $600 \mu \mathrm{g} \cdot \mathrm{day}^{-1}$ and 7 with terbutaline for 6 months. The mean PD20 increased with BUD and decreased slightly with terbutaline, and the difference between treatments was significant. The increase was considerable both in the first and second month of treatment with BUD, but the bronchial responsiveness improved only slightly during the 4 months thereafter. However, in a more recent multicentre study in the Netherlands, the mean airway responsiveness of 116 asthmatic children increased from baseline to 4 months by 1.4 doubling doses of hista- mine compared with placebo [21]. This difference became even greater with further follow-up and did not reach a plateau after the median follow-up period of 22 months.

Thus, the present data, as well as the Dutch multicentre study, demonstrate further improvement in peak expiratory flow rates, their variabilities and bronchial responsiveness for at least 10-22 months. Such continuing improvement in lung function over months indicates the need for long-term treatment with inhaled corticosteroids, especially since side-effects do not accumulate with length of treatment. Therefore, we would recommend that inhaled corticosteroids, once started in asthmatic children not controlled on prophylactic sodium cromoglycate, should be continued. Nevertheless, the use of inhaled corticosteroids should be considered carefully and the minimal dose required to control the asthma should be used for regular treatment.

\section{References}

1. Warner JO, Götz M, Landau LI, et al. Management of asthma: a consensus statement. Arch Dis Child 1989; 64: 1065-1079.

2. Warner JO, Neijens HJ, Landau LI, et al. Asthma: a follow-up statement from an international paediatric asthma consensus group. Arch Dis Child 1992; 67: 240-248.

3. Kamada AK, Parkes DP, Szefler SJ. Inhaled glucocorticoid therapy in children: how much is safe? Pediatr Pulmonol 1992; 12: 71-72.

4. Kamada AK, Szefler SJ, Martin RJ, et al. Issues in the use of inhaled corticosteroids. Am J Respir Crit Care Med 1996; 153: 1739-1748.

5. Zadik Z, DeLacerda L, DeCarmargo LAH, Hamilton BP, Migeon CJ, Kowarski AA. A comparative study of urinary 17-hydroxycorticosteroids, urinary-free cortisol and the integrated concentration of plasma cortisol. $J$ Clin Endocrinol Metab 1980; 51: 1099-1101.

6. Holt PR, Lowndes DW, Smithies E, Dixon GT. The effect of an inhaled steroid on the hypothalamic pituitary-adrenal axis: which test should be used? Clin Exp Allergy 1990; 20: 145-149.

7. Law CM, Marchant JL, Honour JW, Preece MA, Warner JO. Nocturnal adrenal suppression in asthmatic children taking inhaled beclomethasone dipropionate. Lancet 1986; i: 942-944.

8. Nikolaizik WH, Marchant JL, Preece MA, Warner JO. An evaluation of endocrine and lung function after treatment of asthmatic children with beclomethasone dipropionate and budesonide. Am J Respir Crit Care Med 1994; 150: 624-628.

9. Nikolaizik WH, Marchant JL, Preece MA, Warner JO. Nocturnal cortisol secretion in healthy adults before and after inhalation of budesonide. Am J Respir Crit Care Med 1996; 153: 97-101.

10. Cockcroft DW, Killian DN, Mellon JJA, Hargreave FE. Bronchial reactivity to inhaled histamine: a method and clinical survey. Clin Allergy 1977; 7: 235-243.

11. Cockcroft DW, Berscheid BA, Murdock KY. Measurement of responsiveness to inhaled histamine using FEV1: comparison of $\mathrm{PC} 20$ and threshold. Thorax 1983; 38: 523-526.

12. Hallen B, Uppfeldt A. Does lidocaine-prilicaine cream permit painfree insertion of i.v. catheters in children? Anesthesiology 1982; 57: 340-342.

13. Tanner JM, Whitehouse RH, Cameron N, Marshall WA, 
Healey MJR, Goldstein H. In: Assessment of Skeletal Maturity and Prediction of Adult Height (TW2 method). 2nd Edn. London/New York, Academic Press, 1983.

14. Polgar G, Promadhat U. In: Pulmonary Function Testing in Children. Techniques and Standards. Philadelphia, W.B. Saunders Co., 1991.

15. Tabachnik E, Zadik Z. Diurnal cortisol secretion during therapy with inhaled beclomethasone dipropionate in children with asthma. J Pediatr 1991; 118: 294-397.

16. Phillip M, Aviram M, Leiberman E, et al. Integrated plasma cortisol concentration in children with asthma receiving long-term inhaled corticosteroids. Pediatr Pulmonol 1992; 12: 84-89.

17. Doull IJM, Freezer NJ, Holgate ST. Growth of prepubertal children with mild asthma treated with inhaled beclomethasone dipropionate. Am J Respir Crit Care Med 1995; 151: 1715-1719.
18. Ninan TK, Russel G. Asthma, inhaled corticosteroid treatment, and growth. Arch Dis Child 1992; 67: 703705.

19. Price JF. Corticosteroids and other anti-inflammatory agents in the treatment of children. Eur Respir Rev 1994; 4: 27-32.

20. Kerrebijn KF, van Essen-Zandvliet EEM, Neijens HJ. Effect of long-term treatment with inhaled corticosteroids and beta-agonists on the bronchial responsiveness in children with asthma. J Allergy Clin Immunol 1987; 79: 653-659.

21. van Essen Zandvliet EE, Hughes MD, Waalkens HJ, Duiverman EJ, Pocock SJ, Kerrebijn KF. Effects of 22 months of treatment with inhaled corticosteroids and/or beta ${ }_{2}$-agonists on lung function, airway responsiveness, and symptoms in children with asthma. Am Rev Respir Dis 1992; 146: 547-554. 